\title{
Firm-Level Analysis of Global Supply Chain Network: Role of Centrality on Firm's Performance
}

\author{
Kayvan Miri Lavassani $^{1}$ (D) $\cdot$ Bahar Movahedi $^{1}$ (D)
}

Received: 7 November 2020 / Accepted: 9 June 2021 / Published online: 23 June 2021

(c) This is a U.S. government work and not under copyright protection in the U.S.; foreign copyright protection may apply 2021

\begin{abstract}
Over the past few years, academics and practitioners have started paying more attention to analyze and understand value creation and business models from a business ecosystem perspective. Such business ecosystems have been constructed based on the connected networks of people, firms, industries, and countries. Developing strategies to help sustain the firms' competitive advantage in business ecosystems is a key challenge for businesses and policymakers worldwide. Recent disruptions to global supply chains due to the COVID-19 pandemic have exposed the high risk and challenges of managing sustainable global and intertwined supply chain networks. Using the data mined from financial records, the present study constructs the global supply chain network of the auto manufacturing sector. The data from 32,396 notable first-tier forward and backward supply chain connections were mined to build the global supply chain network in this sector. The global supply chain network structure was analyzed using centrality measures and clustering analysis. We utilized path analysis to explore the effect of various supply chain centrality measures on firms' financial performance, investment risk, and market value volatility. The findings provide new insight into our understanding of the relationship between the firm's location characteristics in the global supply chain ecosystem and various aspects of the asset's performance. Furthermore, discussions are presented about strategies that support sustainable collaborative value creation and sustainable competitiveness of businesses across the global manufacturing ecosystems. The research method used in this study has the potential to be applied to several industries.
\end{abstract}

Keywords Global supply chain network · Business ecosystem · Coopetition · Auto manufacturing · Value creation · Firm performance $\cdot$ Global network centrality

\section{Introduction}

During the past few decades, organizations have experienced significant transformation in their business models. In specific sectors, the competitiveness, which was traditionally measured with regards to the relationships among the businesses, has become primarily among their supply chain. In recent years, we have observed firms exhibited their competitiveness among business ecosystems. The leading players in the ecosystems not only compete with each other but also are engaged in significant cooperation and collaboration (Lavassani, 2017). It is not surprising to see companies collaborating and compete with each other at the same time in the same market. This cooperation among competitors

Kayvan Miri Lavassani

Kayvan@Lavassani.ca

1 School of Business, Noth Carolina Central University, Durham, USA to create a "win-win" outcome is known as "coopetition" (Basole et al., 2015). If the leading players in the business ecosystem cannot maintain the "win-win" outcome of the cooperation, the coopetitive environment will have less cooperation, and consequently, the ecosystem participants may face challenges with regard to value creation and maintaining sustainable competitiveness. However, one of the main challenges facing researchers and practitioners has been determining competition and collaborators' domain. Understanding "Who is competing with who?" and "Who is collaborating with whom?" has become more complicated in the connected supply chains that expand across industries and continents. The first goal of this study is to empirically identify the clusters of competing firms and the individual collaborating firms in the auto industry, as an industry with an expansive global supply chain. The second goal of this study is to explore how a firm's position in the global supply chain can affect its financial performance, asset risk, and market value volatility. 
Basole et al. (2018) argue that "research in the supply chain area inherently involves the study of supply networks", and "real-world supply networks are characterized by a complex network of interfirm relationships"; hence, it is critical to explore the role of supply chain network characteristics on the firms' performance. While few scholars have identified the literature gap, different approaches have been used to explore this domain. For example, De Mello-Sampayo (2017) highlighted the importance of such a study in her study at the country level. Her work involves the utilization of gravity models for import-export data at the country level. To the best of the authors of this study's knowledge, no previous research has utilized neither the firm-level data nor the network analytics technique to study value chains using comprehensive global supply chain data. Recent studies have started paying more attention to the role of centrality measures in the operation of supply chains. This recent interest in centrality and firms' position in supply chain network stems from the increasing application of network science to the study of the supply chain where each firm is viewed as a node while their forward and backward relationships are viewed as edges (Zhao et al., 2021). Seiler et al. (2020) have called for a need to incorporate network analytics tools in "performance measurement." Recently few works have started to explore the effect of firms' position in the supply chain network on firms' performance. For example, Seiler et al. (2020) examined the relationship between firms' performance and their location properties in "a small sample size" from Germany. Considering the noticeable globalization in many industries-in particular in the auto industry - "networks formed of supply chains are typically large and complicated," and hence there is a need to conduct such research using large-scale global data, which is the subject of this study (Seiler et al., 2020).

Furthermore, several other studies have highlighted the role of network view in other aspects of supply chain performance. For example, Li (2021) recommends the application of neural networks to improve supply chain flexibility. Another example is Dixit et al. (2020)'s work, where they explore the application of supply chain network analysis in studying the supply chain's resiliency. Based on the study of 23 firms in India, Dixit et al. (2020) discuss how supply chain managers can influence firms' centrality to influence firms' connectivity and resilience. Since access to largescale data about the firms' internal operations is not feasible at the global scale, we measure resiliency from a financial asset performance perspective. In the following section, the discussion about the origins of business ecosystem studies and our approach to network analysis in this domain is discussed. After exploring the application of network analysis in global supply chains, we discuss the research methodology and data collection. Finally, after discussing the study results, recommendations for future studies and the limitations of the current study are presented.

\section{From Natural Biological Ecosystems to Business Ecosystems}

Ludwig von Bertalanffy was one of the seminal contributors to the development of systems theory, specifically through his contributions during the 1950s (c.f. Bertalanffy, 1950). Bertalanffy's contributions to the methodology of science were mostly from a physics and biology perspective. For example, in his paper published in 1950-while he was a professor at the University of Ottawa-Bertalanffy analyzed the open system view of equilibrium of living organisms compared to the close systems. His research before the 1950s was mostly from a biology perspective, which led to the development of organism system theory. After the 1950 s, his research was mainly around the methodology development of science, which led to the development of the General System Theory (GST). The present work follows Ludwig von Bertalanffy's (1968) holistic view of the GST. Thacker (2004), in his work on molecular biology and computer science, describes Bertalanffy's holistic view of the organisms as "systematic interactions of the parts as a whole," which is defined "in opposition to reductionism." The present study's goal is to go beyond the analysis of the elements of the business ecosystem and explore the globalized business ecosystem as a holistic system based on the available data and computational limits.

When the term ecosystem is used in its plural form throughout this paper, it refers to the competing sub-ecosystems (i.e., clusters of firms). From this perspective, competition occurs among clusters within the holistic, connected business ecosystem rather than isolated and independent groups. These clusters of connected organizations create the global supply chain business ecosystem, which was first described by Moore (1993) in his influential work on the "ecology of competition."

Based on the anthropological study of the social system and biological natural ecosystem, Moore $(1993,1996)$ argues that firms-as actors in the network-"coevolve their capabilities and roles" (Moore, 1996, as cited in Graca \& Camarinha-Matos, 2017). Moore further describes how natural ecosystems collapse and are replaced by new ecosystems; this is a systemic approach with applications in the study of business ecosystems (Moore, 1993). Moore (1993) argues that a business ecosystem is not limited to one industry but "crosses a variety of industries." However, this view of business ecosystems was at the theoretical level, and the researchers could (until now) only explore business ecosystems through limited case studies or small-scale work. This study will use advanced data mining and data analysis sources to construct and explore cross-industry and global 
business ecosystem in auto manufacturing. We will address the "cross-industry" characteristic of the business ecosystem through a one-tier analysis of the supply chain. Our data mining and analysis can be extended in future studies to include multi-tiers of the supply chain. While the one-tier examination of the global supply chain will consist of tierone backward and tier-one forward supply chain actors from other industries, the higher-tier global supply chain network will further uncover the underlying patterns of the business ecosystem. The study of the supply chain beyond the one-tier is fruitful and feasible work that can be a subject of future studies.

\section{Supply Chain and Firms' Ecosystem Boundaries}

Traditionally setting firms' boundaries involved strategic decisions about "which business activities should be brought within the boundary of the firm? and which business activities should be outsourced?" (Barney, 1999). In today's "international production networks," the competition is not only focused on the "final goods" and services but also involves the entire intermediate supply chain of products and services (De Mello-Sampayo, 2017). The integration of the supply chain into local actors of the network of goods and services completes the "firms' ecosystem" (Taglioni $\&$ Winkler, 2016). Therefore, the business strategists and policymakers need to recognize the boundary of their business ecosystem as well as the boundary of their competitors' business ecosystem. We will provide further discussion in the data analysis section about using a clustering algorithm to identify network communities and competition boundaries.

In the traditional view of the firm's boundary setting, the focus has been on minimizing "transaction cost" and maximizing the "dynamic capability" (Gulbrandsen et al., 2017) to enhance the firms' competitive position. McCormack et al. (2002) further argue that competitive advantage can be achieved not only through a vertically integrated supply chain (minimizing transaction cost), but also through the firm's integration in the "networked community" that provides firms with dynamic capabilities; or what Reeves and Deimler (2011) refer to as "second-order" capabilities. The inter-organizational business processes are the "glue" that creates such a "networked community" (McCormack et al., 2002). Petricevic and Verbeke (2019), based on the study of inter-organizational collaborations, argue that such network connections create synergies that enhanced firms' competitive advantage through elevating the firms' dynamic capabilities. Therefore, our first hypothesis in the study is that firms that are more strategically integrated into the industry supply chain will have a higher financial performance level due to transaction cost advantages. Our second hypothesis is that firms that are more strategically integrated into the industry supply chain will become more resilient due to their dynamic capabilities; we hypothesize that higher resilience would be reflected in the firms' market value volatility and risk assessment of the financial assets-as measured by Beta.

Firms' competitiveness stem from the multi-level interaction of firms' business ecosystem at the country, industry, and firm levels. Competitiveness can be studied both at the macro- and micro-levels (Momaya, 2019). The current study's focus is to explore competitiveness in terms of asset performance at the firm-level, which is a micro-level view. Firms can achieve higher competitiveness levels by focusing on their assets, processes, and performance (Momaya, 2001). The firms' position in the supply chain network can be viewed as one of the second-order assets. We do not explore the intra-organizational processes due to the lack of access to such data on a large scale; however, we explore inter-organizational relationships by analyzing network properties and community memberships.

In the following section, a discussion of network centrality is presented to discuss our analysis of the firm's strategic location in the connected supply chain network. Network centrality is a mathematical measure of the importance of a node in a network. In our study, each node is a firm, and the directed edges represent the supply chain relationships. There are various centrality measures; each centrality measure determines firms' influence (or importance) in the network from a different perspective. Some measures (i.e., degree) are local measures while others are global measures (i.e., pagerank). While a local centrality measure only considers the immediate customers/suppliers relationships, a global centrality measure considers the whole supply chain network to measure a firm's influence in the supply chain network.

\section{Business Ecosystem and Transaction Cost}

Ronald Coase, Chester Barnard, and Herbert Simon are among the early authors who describe the contributions of transaction cost theory in firms' existence (Scott, 2003; Williamson, 2005). The early studies on supply chain management have been focused on intra-organizational operations (Pitelis \& Wahl, 1998, as cited in Foss, 1999). Williamson $(1975,1981)$ further expanded the application of transaction cost theory to inter-organizational operations by highlighting transaction cost theory's role in promoting vertical integration and trust across connected businesses. Further advancements in supply chain management promoted the process-oriented view of supply chain operations that explore intra- and inter-organizational processes simultaneously (c.f. Lavassani \& Movahedi, 2018). The present study focuses on the inter-organizational approach of the supply chain analysis, where supply chains are viewed as 
interconnected networks of firms. The unit of analysis in this study is the firm and inter-organizational networks are examined. Studying the supply chain networks at the process level through an intra-organizational network of processes could be a fruitful subject for future studies.

The transaction cost theory explains the vertical connection and integration of various organizational supply chain elements from backward tiers to forward tiers, whether the supply chain is viewed as a connected network or an integrated process. In their well-cited study, Grover and Malhotra (2003) conclude that transaction cost theory applies to organizational supply chain management in four facets: effort, monitor, problem, and advantage. These four facets are briefly explained here: The attempt to "build and maintain the relationship" with suppliers; the cost of "monitoring the performance of suppliers,"; resolving the problems that arise in the business relationships, and engagement of suppliers in "an opportunistic behavior." It is important to note that transaction cost theory is primarily concerned with direct economic factors. However, it is noteworthy to remind managers and policymakers that the management of supply chains involves the management of personnel and human relations (c.f. Yeung et al., 2009) as well as the management of firm-level relationships.

\section{Business Ecosystem and Dynamic Capabilities}

The traditional approach to firms' strategy was based on gaining market "position, scale, and first-order capabilities" (Reeves \& Deimler, 2011) executed based on "hierarchical command and control" (Long \& Vichers-Koch, 1995). However, as Reeves and Deimler (2011) describe, an increasing proportion of leading firms are losing their market position due to the absence of "relative stability" and the business environment's profitability. In such a business environment, the firms' competitiveness and survival depend on acquiring dynamic capabilities (or second-order capabilities). Dynamic capabilities describe the firms' ability "to respond to [the changing] environments by reconfiguring inert and insufficiently flexible ordinary capabilities." (Schriber \& Löwstedt, 2019). A combination of economic forces and social exchange opportunities in the business ecosystem promotes value co-creation (Kohtamäki \& Rajala, 2016). The literature provides supportive evidence that the dynamic capabilities create synergies for inter-connected firms at the network level and the firm level (Petricevic \& Verbeke, 2019).

The concept of ecosystem boundary setting and its importance to firms' competitiveness through transaction cost theory and dynamic capabilities were discussed in this section. As will be discussed in the research methodology section, we will use clustering algorithms to identify the collaborating firms in each competing and collaborating network across the industry. To explore various aspects of firms' connectedness, we use the concept of centrality. In the following section, the concept of network centrality is discussed in the context of firms' supply chains.

\section{Supply Chain and Centrality}

In recent years, there has been increasing attention to the study of global supply chains using neural network techniques (c.f. Moons et al., 2019; Li et al., 2020). Recent studies suggest that network characteristics and the firms' position in the supply chain network are related to the firms' resilience ( $\mathrm{Li}$ et al., 2020) and performance (Moons et al., 2019). With the support of recent advancements in the field, this study aims to empirically explore how various aspects of firms' position in supply chain networks can affect the firms' resilience and performance. We measure a firm's resilience based on its volatility in the market and asset risk assessment. For measuring the financial performance, we will use return on asset as a well-cited and widely applicable measure to all for-profit businesses. Furthermore, we will explore the firms' position in the interconnected supply chain network using various centrality measures.

The concept of centrality has been widely used in network science to measure various aspects of an actor's influence across the whole or a portion of a network. Each measure of centrality assesses the importance and influence of the node (firm) from a different perspective. In the following paragraphs, these centrality measures are briefly introduced in the context of the supply chain. Degree centrality is arguably the most common measure of centrality. Degree centrality is a local measure that is based on the number of connections that a firm has (Nuss et al., 2016). In supply chain networks, the connections are directed, and hence we have the opportunity to differentiate backward (in-degree) and forward (out-degree) supply chain connections. Based on our observations of the data, most of the firms which are closer to the final product (a major part, or an assembled car) have a higher number of in-degree.

In contrast, the part suppliers that offer a variety of components tend to have higher out-degree. This observation is aligned with the previous research (c.f. Nuss et al., 2016) that suggests a positive relationship between in-degree and product complexity, as well as a positive relationship between product variety and out-degree. Dyer and Singh (1998) and Chen and Paulraj (2004) further argue that indegree and out-degree influence a firm's competitiveness and negotiation power. Therefore we hypothesis that firms with higher in-degree and out-degree will have better financial performance. Previous studies have not explored the role of supply chain degree centrality on asset volatility to the best of our knowledge. Therefore our analysis on the latter mentioned relationship will be an exploratory work. 
However, we expect firms with a greater variety of products (high out-degree) to be less volatile.

The connected component measures the reachability of a firm in the network (Tang et al., 2010. Firms with higher reachability are expected to be more stable and experience lower levels of operational disruptions. Closeness centrality is calculated by taking the average of each firm's shortest path (Nuss et al., 2016). This means that closeness is a global centrality measure. In this research, we use harmonic centrality to include firms in disconnected parts of the supply chain network. A firm with higher closeness has is located on longer supply chain paths. As a result, such firms are argued to have a higher risk and uncertainty exposure (Nuss et al., 2016). Therefore, we hypothesis that firms with higher closeness centrality will experience higher asset volatility. Pagerank is another global measure of centrality calculated based on the number of in-degree (suppliers) that a firm has and the importance of those suppliers in the network (Langville \& Meyer, 2011). Our observation shows that firms with higher pagerank are likely to be assemblers of the more complex and probably final products.

Consequently, we hypothesize that firms with higher pagerank centrality will be engaged in the production of more complex products, with higher value-added, resulting in higher profitability. Hub and authority are two interrelated global centrality measures (Benzi et al., 2013). In the supply chain context, hub centrality is the sum of authority centrality of customers (targets) of a firm. In contrast, authority is the sum of hub centrality of suppliers (sources) of a firm (Benzi et al., 2013). Interestingly as we will discuss in our exploratory analysis, hub centrality and out-degree were found to form one construct together while authority and in-degree were categorized together under another construct. Following our discussion on degree centrality, we hypothesis that firms with higher hub centrality will have higher profitability as they are more likely to be manufacturers of final or more complex products. Also, we hypothesis that firms with higher authority centrality will be more stable and will be less volatile assets due to their greater variety of customers.

The number of triangular supply chain network structures connected to each firm is another local measure of centrality (Benzi \& Klymko, 2015). The formation of triangular supply chain connections indicated a higher level of integration and emersion of a firm in its business ecosystem. We test the hypothesis that firms located within denser triangular supply chain structures will be more resilient ( $\mathrm{Li}$ et al., 2020). The bridging coefficient is a measure of bridging centrality in the networks. Firms with higher bridging coefficients play a critical role in connecting the most influential firms (as measured by their degree). Influential firms will have a higher dependency on firms with a higher bridging coefficient. As a result, we hypothesis that firms with higher bridging coefficients will have higher profitability.
Betweenness-similar to bridging coefficient-is a global centrality measure (Rajeh et al., 2021). However, unlike the bridging coefficient that focused on high degree firms, betweenness centrality is a nondiscriminatory measure that calculates the ratio of shortest paths throughout the supply chain that has to go through each firm (Hanaka et al., 2017). We hypothesize that a firm with higher betweenness will be more resilient and less volatile since more firms (large and small) have some level of dependency on a firm with a higher betweenness centrality.

Another centrality measure that we used in this study is cluster size centrality (CSC). We propose using CSC in supply chain network analysis as it provides a unique centrality measure based on a global community clustering algorithm (c.f. Leskovec et al., 2009). The only other community centrality measure used in this study to provide community information is triangle centrality, which provides limited information as it is a local centrality measure. We are not aware of any previous study to use this centrality measure in empirical research on supply chain networks. We calculated cluster size based on the community clustering result produced using Blondel et al. (2008) community clustering algorithm. After identifying each firm's cluster membership, we count the number of firms that are determined to be in the same cluster as each firm. The result is a global measure of community centrality. Firms with higher CSC are expected to be more involved and immersed in larger sub-ecosystem and may experience higher asset value stability and have low uncertainty. Our clustering algorithm identified $361 \mathrm{com}-$ munities or business ecosystems. Appendix 1: Table A1 (All Appendices are in supplementary file) displays the five largest clusters in our sample. In each cluster, we have displayed the 20 most influential firms as measured by eigenvector centrality. Eigenvector centrality is the last centrality measure that was utilized in this work. The eigenvector is arguably one of the most commonly used global measures of centrality (Besri \& Boulmakoul, 2017; Li et al., 2020). The eigenvector of a firm depends on the importance of other firms connected to the firm. We hypothesize that firms linked to more influential firms in the supply chain network will have better financial performance and lower volatility. In this study, we utilize various measures of network centrality to identify different aspects of firms' position in the supply chain. As one of the early studies in this domain, we will utilize exploratory analysis to determine the "underlying pattern of relationships" among the mentioned measures of centrality (Baglin, 2014).

Based on our search of the literature to the best of our knowledge, the early studies on global connections from a network's view focused on exploring the role of social relations in establishing alliances (c.f. Gulati, 1995; Gulati \& Garguilo, 1999). It is well established in the literature that "a firm's high density of direct and indirect relationships" 
in the connected network of firms is evidence of the firm's "experience and expertise in navigating networks" as well as its access to tangible and intangible resources (Guillot \& Lincoln, 2001). More recent studies have further advanced our understanding of the role of supply chain networks on marketing integration (Stolze et al., 2018), the resilience of the supply chain (Dixit et al., 2020), and firm performance (Li et al., 2020). However, to this date, no study has used large-scale network data to conduct such research globally using supply chain network large-scale data.

\section{Data Collection Research Methodology}

The data for this study are obtained from Innovation \& Entrepreneurship Business Ecosystem Lab (IEBE Lab). IEBE Lab gathers business ecosystem and network data through the data mining of financial sources from public announcements of the firms and their formal financial filing (particularly the publically traded firms), including $10 \mathrm{~K}$ forms and 10Q forms. Naturally, this method will only collect data about the leading suppliers and customers of the firms. One limitation of this method is that only the formally announced customers and suppliers will be included in the database; however, this is still the best available data of this kind. Another limitation in data collection is concerning the collection of financial and operational information. Since many private companies (unlike the publically traded firms) do not have an obligation to publish their financial and operational data, we have financial and market data primarily for the publically traded firms. Our data on the supply chain network are more comprehensive in comparison to the financial and market data. The reason is twofold: first, while private firms are hesitant to announce their financial data, these firms may find benefit in announcing their leading suppliers and customer, and second, the supply chain network data of private firms that are having notable collaboration with publically traded companies around the world are announced in the publications of publicly traded firms. The fact that the auto industry has a large number of small firms (mostly private) and a small number of large firms (mostly publically traded) (IBISWorld, 2017) provides an excellent opportunity to extract supply chain data from the relatively few large publically traded firms. In the following section, the global supply chain network of the auto industry is discussed.

\section{Auto Industry Business Ecosystem}

This study provides a framework for investigating and analyzing the complex global manufacturing business ecosystems. The present research primarily focuses on the auto industry as a manufacturing sector with an extensive international and domestic value chain in virtually every country. The auto industry includes a "large number of small players" and several large corporations around the world (IBISWorld, 2017). For example, the tier-one OEM suppliers only carry about $5 \%$ of the "parts and accessories" revenue, and the top 75 suppliers contribute to less than $50 \%$ of the industry review. Small suppliers from around the world (IBISWorld, 2017) generate over half of the revenue in this sector. Guo et al. (2016), in their study on the auto manufacturing supply chain, argue that such "complex [and] multi-commodity" should be studied from a "network structure" perspective (c.f. Chen et al., 2020). These factors make the auto industry an exciting sector to investigate, especially considering its global reach throughout its value chain. Our unique data mining source enables us to construct a single-tier value chain and multi-tier value chains. This study is focused on the first-tier supply chain, which includes first-tier customers and first-tier suppliers. Figure 1 displays a visualization of the network analysis based on the data obtained in October 2019. While this study's focus is not on the centrality analysis within the supply chain network, it is noteworthy to mention the critical influence (measured in terms of network centrality) of Indian and Chinese steel and auto manufacturing firms along with the legacy car manufacturers. The high levels of centralities displayed in Fig. 1 are aligned with past research in the area that reports the increasing role of Chinese and Indian firms in such industries (Deshmukh \& Haleem, 2020) and the dominant position of few legacy auto manufacturers (IBISWorld, 2017).

While the study of various centrality measures and graph analysis could be the subject of future studies, here we briefly mention some of the network visualization implications displayed in Fig. 1. Bridging centrality is one of the tools for identifying influential firms that play an important role in connecting other influential firms in the supply chain. In the case of the top network (Fig. 1), Tata Steel, as a raw material supplier to other major part manufacturers, is among the most influential firms. Tata Steel provides essential raw materials, and it is part of a large conglomerate of firms that many of them contribute closely to the auto industry. At least 25 firms are identified in our database as members of the Tata conglomerate (Appendix 1, Table A2). We identified these firms by searching the keyword "Tata" in the name of the firms. There could be firms that are a member of the Tata group or closely associated with this conglomerate, but we could not identify them. The relatively high bridging centrality of Tata Steel could be the result of both its role are a supplier of critical raw material and Tata Steel's expanded influence in the auto industry through the firm members of its conglomerate.

The middle visualization (Fig. 1) identifies the most influential firms based on their betweenness centrality levels. Betweenness centrality measures the ratio of shortest paths that goes through each firm. Firms with the highest betweenness centrality act as bridges connecting many 
Bridging Centrality*

Betweenness Centrality*
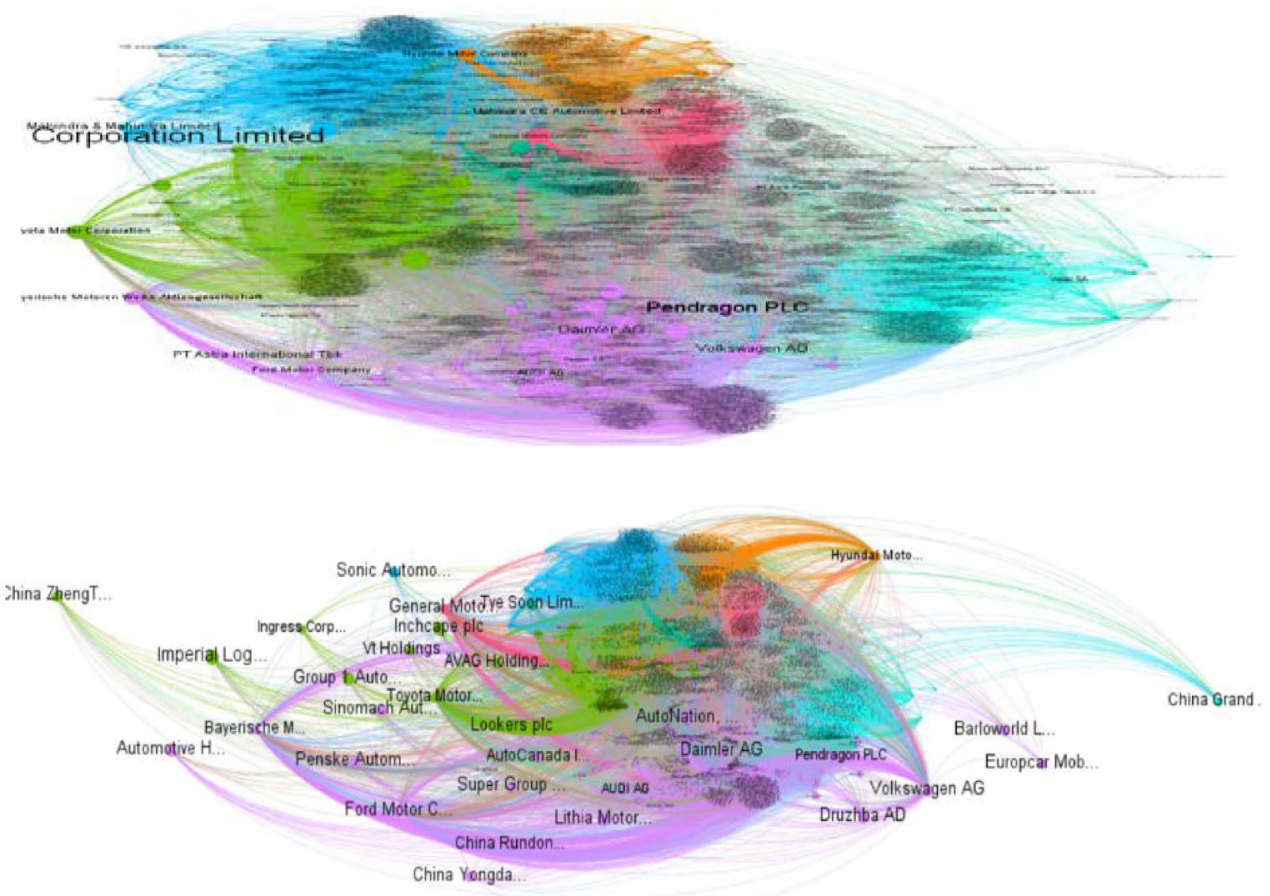

Fig. 1 One-tier Visualizations of Global Auto Supply Chain Network. * Colors distinguish clusters based on Blondel et al., (2008) community clustering algorithm. Node size represents eigenvector centrality. Font size represents bridging centrality, betweenness centrality, and

firms or even connecting clusters of firms. In our study, most of these firms are major part suppliers and include some legacy auto manufacturers. The bottom visualization (Fig. 1) displays the most influential firms as measured by their eigenvector centrality. The eigenvector is calculated based on the influence of firms' forward and backward connections. Firms with higher eigenvector centralities can have a notable impact across the whole network. Most of these firms are legacy auto manufacturers as well as some major part suppliers. As a result, there is less eigenvector centrality variance among the highly central firms. This result is in contrast with bridging and betweenness centralities, where one or a very few firms were shown to have notably higher centrality. It is important to note that
Eigenvector centrality, respectively (from top to bottom). Clustering analysis data available at https://github.com/businessecosystem/ AutoSupplyChain

the current analysis is based on a one-tier analysis of the supply chain. We expect the network structure to change to some extent as the data are collected from higher-tier supply chains.

The auto industry has significant complexity in terms of its global network of operations. The auto industry's ecosystem brings together up-stream and down-stream collaborating firms as well as the competitors, creating what we refer to as a coopetitive ecosystem. This coopetition promotes the rapid growth of global auto manufacturing ecosystems since the 1980s with the "growth in the popularity of alliances between competitors" (Burgers et al., 1993). Operating in a coopetitive business ecosystem is recommended as a strategy of choice for achieving sustainable competitive 
advantage in the auto industry (Calleja-Blanco \& GrifellTatje, 2016).

Many businesses have experienced moving from a rational and natural view of their business models to the open system perspective. In such an environment, there is a greater need to assess companies based on the industry ecosystem rather than merely "from the focal firm perspective" (Burgers et al., 1993; Ritala et al. 2014). This open system view of businesses will require the study of networks, subnetworks, and collaborations in the business ecosystem.

Exploring business ecosystems can be conducted from different perspectives, each providing valuable inputs, and insights. For example, Basole et al. (2015) explore the telecommunications industry's business ecosystem using information about mergers and acquisitions in the industry. Considering the auto industry's characteristics, including the global spread of the industry, we use the movement of intermediary and final products and services to explore this ecosystem. While this study's results may not be generalized to other manufacturing sectors, the study's methodology and framework can be easily replicated in other industries.

\section{Research Methodology}

The research idea was developed based on the previous literature search on business ecosystems and the feasibility of access to supply chain data based on the mining of financial records. Notable resources were utilized to create supply chain network data. R software and Gephi software were used for data preparation, calculating various centrality measures, conduct clustering analysis, and produce visualizations. After cleaning the data, the financial measures were collected from financial databases for evaluating multiple aspects of the firms' performance. Exploratory Factor Analysis (EFA) was conducted using SPSS software. Centrality measures and financial measures were analyzed using path analysis. Path analysis was performed using LISREL software. Modifications were made to the research model based on exploratory and path analysis results. Finally, fitness analysis was conducted. Figure 2 presents the research methodology in the diagrammatic form.

The present study uses data mined from financial sources filed by major public corporations and formal news announcements published in reputable financial publications.

We conducted network analysis to measure various aspects of centrality for each firm as well as clustering. Furthermore, we explored the effect of centrality measures on firms' financial performance using exploratory and path analysis approaches. Based on the previous work on firms' performance and collaboration (c.f. Graca \& CamarinhaMatos, 2017), we hypothesis that firms with higher centrality in their global supply chain network will have a better performance due to their role in the network which enables collaborations as well as more robust asset risk management and lower market volatility. The conceptual research framework is presented in Fig. 3.

In this conceptual framework, we initially assumed dependent variables' independence as the nature of the work is exploratory. As will be discussed later in the analysis section, risk and volatility were identified to represent separate constructs. Additionally, the analysis suggested the dependence of risk and volatility on the firms' financial performance, supporting the past literature in the field. In
Fig. 2 Research methodology steps

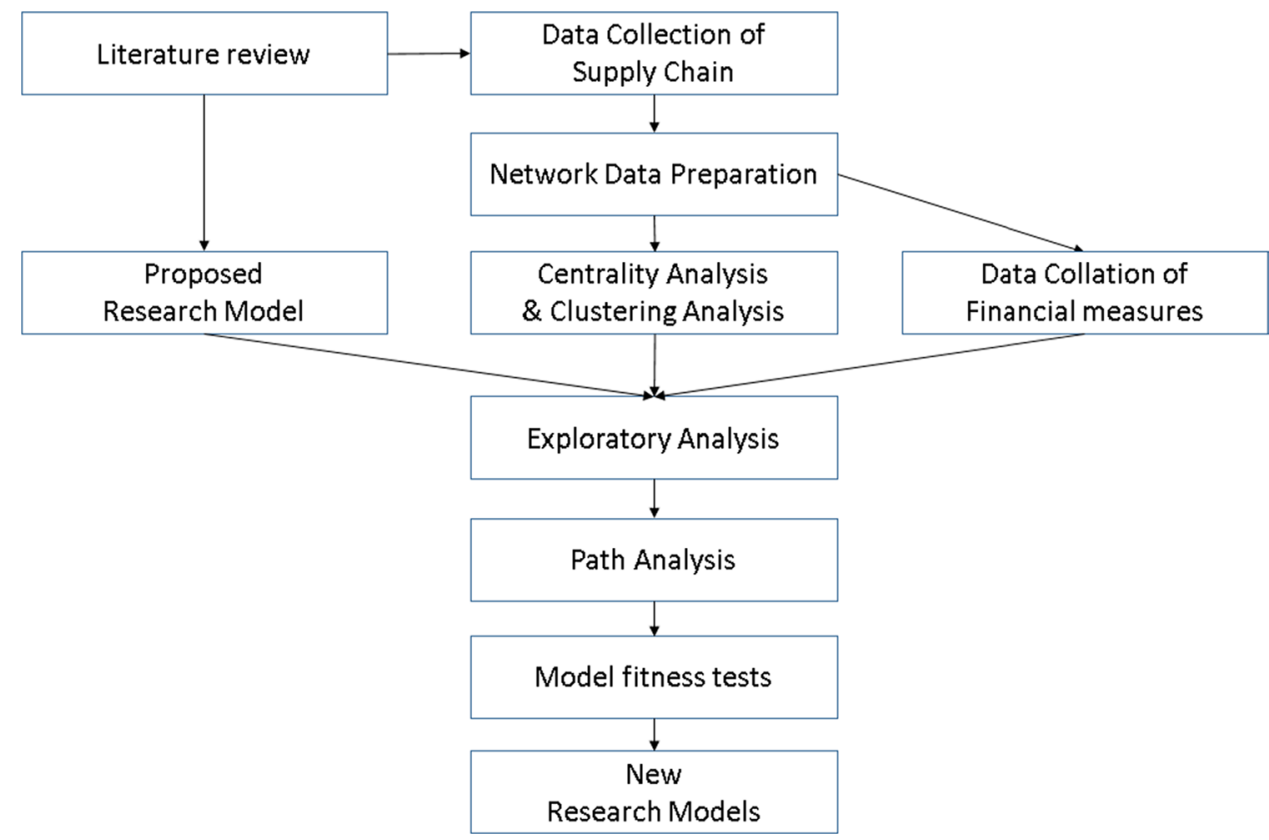


Fig. 3 Conceptual framework of relationships

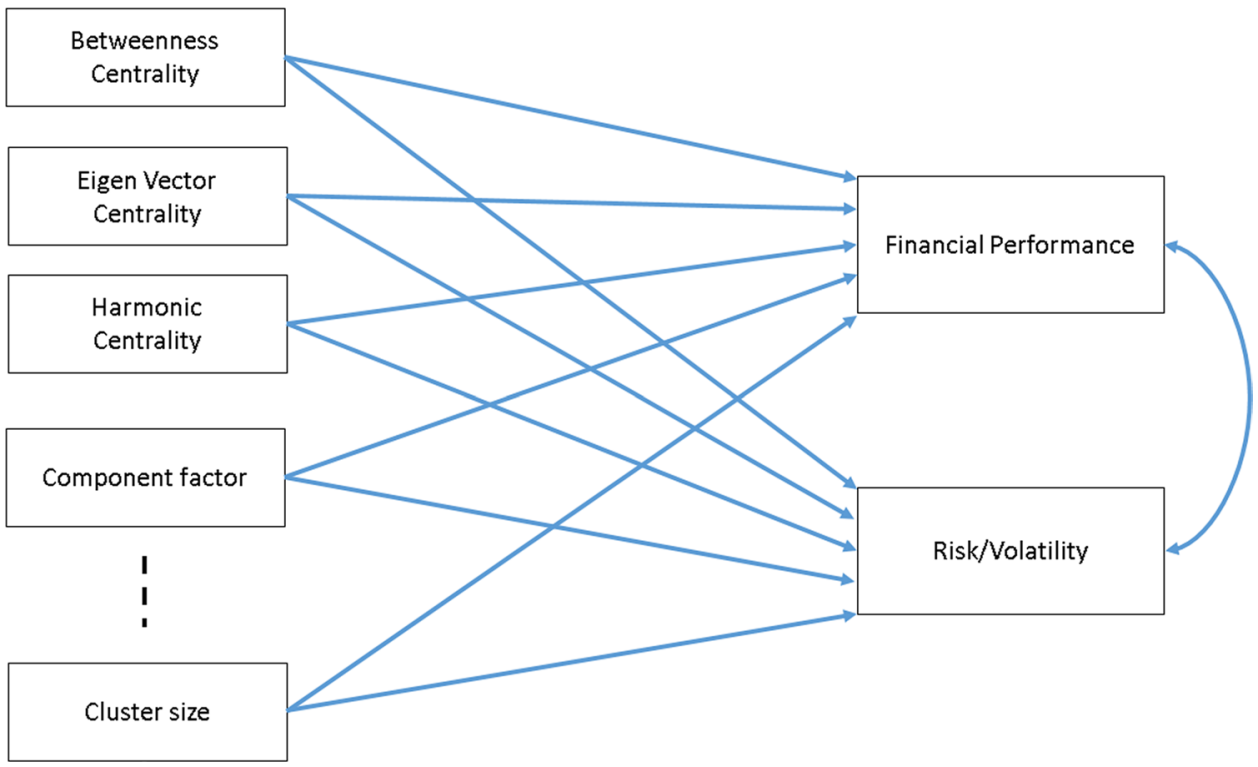

the following section, data collection and data analysis are discussed.

\section{Data Collection and Data Structure}

Financial publications (including Securities and Exchange Commission (SEC) filings along with formal announcements) are the primary source of data for this study. The data were collected from companies classified as "automobile and components," under the "consumer discretionary" category according to the Standard Industry Code (SIC) classification. Our initial database includes 32,396 firms around the world categorized into 438 unique industry codes. The initial sample included all of the firms classified in this sector in financial databases, including
Compustat and SNL Financial. The data were last updated in October 2019. Figure 4 displays the distribution of the industries across top industry sectors within the automobile and components sector. The financial reports only include the "notable" suppliers. We define notable suppliers as per the SEC segment reporting requirement. SEC requires publicly traded firms and select private firms to report customers and suppliers that contribute to publicly traded firms' costs and revenue to a certain level. To produce the most comprehensive supply chain network, we extract the data separately about "forward" and "backward" supply chains of each legal entity. Data extracted from the firms' financial filings are developed based on the firms' legal entities around the world. For example, in the case of Toyota, we have 69 legal Toyota entities worldwide

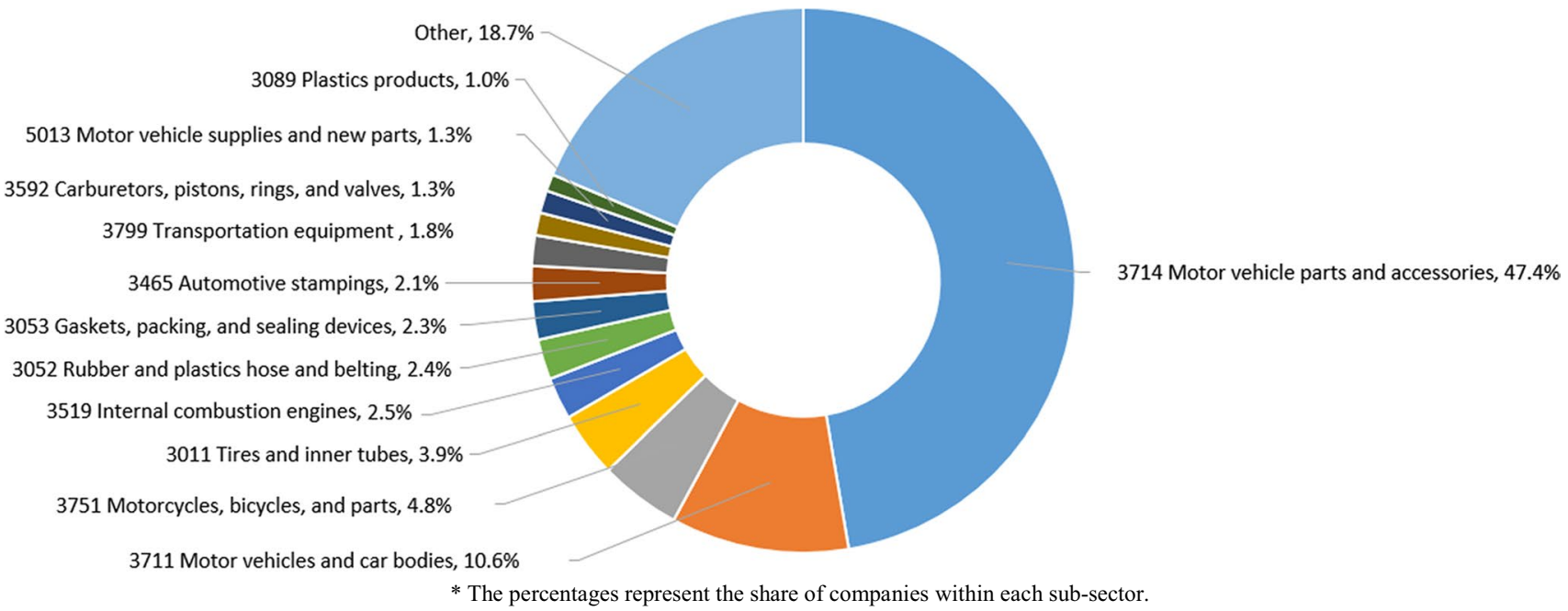

Fig. 4 Industries within the automobile and components sector* 
(see Appendix 1, Table A3), and we develop the supply chain for each legal entity separately.

After collecting the list of companies from our target industry, the next step is to extract the data about their supply chain. The present study focuses on forward and backward supply chains associated with primary activities and support activities. The following actors were identified to be involved in the backward and forward supply chain: suppliers, customers, client service providers, licensees, licensors, distributors, tenants, landlords, lessees, lessors, borrowers, creditors, transfer agents, and vendors. Based on the available published data in financial publications, we could obtain the main backward and/or forward actors for 4,470 firms. In total, the first-tier supply chain in our data includes 13,662 directed edges with forward supply chain actors and 17,213 directed edges with backward supply chain actors. We started our data collection with 32,396 unique firms. After removing the firms that we did not have information about their first-tier forward and backward supply chains, we ended up with 11,122 unique actors (firms) in the auto supply chain. The measures of centrality, as well as clustering analysis, were calculated using all 11,122 data. Since our research of firms' performance and volatility is focused only on firms active in the automobile and components sector, the sample was further narrowed down to 3,316 firms in the automobile and components sector. It is important to note that while for tier-one supply chain analysis, we are narrowly focused on the auto industry, however, the supply chain network characteristics are calculated based on the sample of 11,122 supply chain connection to capture the structure of the global network of the firms' tier-one supply chain that crosses the primary industry.

\section{Data Analysis}

We started with calculating centrality measures, particularly degree (in-degree, out-degree), harmonic closeness, betweenness, bridging coefficient, authority, hub, triangle, pagerank, and eigenvector. We also calculated the cluster size to investigate its role in firms' performance and risk. The financial performance and volatility data were also collected from the financial databases. Some literature suggests the possibility of a time-lag between financial/volatility indicators and organizational or supply chain structures. Supply chain networks of firms are developed over a relatively long period in the firms' history and change gradually, while financial and volatility indicators may have a faster rate of change in some cases. To address this issue, the financial and volatility data are collected for three periods: the most recent fiscal year, 2 years prior, and 5 years prior. After preparing the data, we conducted exploratory and path analyses to investigate the role of supply chain centrality on firms' performance.

\section{Exploratory Data Analysis: Centrality, Volatility, and Performance}

EFA was conducted to explore the underlying patterns of various aspects of centrality. Several centrality measures were calculated to measure multiple characteristics of firms' supply chain position in the auto industry. These measures include in-degree, out-degree, betweenness, hub, cluster size, closeness, harmonic closeness, bridging coefficient, bridging, authority, triangle, pagerank, and eigenvector centrality. All of the above measures, except for cluster size, are commonly used to study network structures. We added cluster size as the literature suggests companies operating in larger ecosystems tend to have more stable operations that can affect their financial performance and market volatility performance. We define the firm's cluster size as the number of firms that are identified to be members of each firm's cluster, as determined by the clustering algorithm (c.f. Leskovec et al., 2009).

SPSS software was used to conduct the exploratory analysis. Several iterations of the model were tested to identify the best model that fits the measures of centrality. In this section, some significant steps of the analysis are described. As it is standard practice in EFA, the decision about design of the model was not merely based on the outcome of dimension reduction performed through SPSS; instead, we also considered each measure's conceptual and theoretical support. In the first step, communality analysis was conducted, and any measure with the extraction of less than $0.3-0.5$ was removed. In the second step, we assessed the total variance explained tables of various models to see the model's expected number of factors. The number of components with an eigenvalue of greater than 1, provides a guideline about the number of factors in the model. According to this analysis, we expected to have a 5-factor model. In the third step, varimax rotated component matrix was produced to identify the factors. Factor loading of less than 0.4 was not reviewed. A five-factor model was identified after several rounds of data-reduction analysis in SPSS. The number of factors was found to be aligned with the result of the suggested factors recommended through a review of the total variance explained. Table 1 displays the rotated component matrix.

We also checked the correlation among measures of centrality to ensure there is no strong correlation between any pair of factors (Appendix1, Table B5). The findings from the exploratory analysis are presented in the discussion of the findings.

KMO and Bartlett's test was conducted to assess the sample size (Table 2). The identified KMO of 0.701 is considered acceptable as the desired threshold is usually above 0.5. Bartlett's test of sphericity is also significant according.

After determining the factors, we conducted tests of the reliability of the factors using Cronbach's Alpha and 
Table 1 Rotated component matrix for measures of centrality

\begin{tabular}{llllll}
\hline & \multicolumn{3}{l}{ Components } & & \\
\cline { 2 - 5 } & 1 & 2 & 3 & 4 & 5 \\
\hline In-degree & .971 & & & & \\
Out-degree & & .826 & & & \\
Closeness centrality & & & & .855 & \\
Betweenness centrality & .749 & & & & .985 \\
Bridgingcentrality & & & & & \\
Authority & .918 & & & & \\
Hub & & .931 & & & \\
Triangles & & & .817 & & \\
Strong component & & & & .763 & \\
Pagerank & .883 & & & & \\
Cluster size & & & .807 & & \\
Eigenvector centrality & .954 & & & & \\
\hline
\end{tabular}

Closeness centrality data are reversed rank-order

Table 2 KMO and Bartlett's test

\begin{tabular}{lll}
\hline $\begin{array}{l}\text { Kaiser-Meyer-Olkin measure of } \\
\text { sampling adequacy }\end{array}$ & .701 \\
Bartlett's test of sphericity & Approx. $\chi^{2}$ & $10,458.814$ \\
& $\mathrm{df}$ & 66 \\
& $\mathrm{Sig}$ & .000 \\
\hline
\end{tabular}

Table 3 Average variance extracted and composite reliability

\begin{tabular}{llllll}
\hline Components & 1 & 2 & 3 & 4 & 5 \\
\hline AVE & .81 & .77 & .66 & .67 & .97 \\
CR & .95 & .87 & .79 & .79 & .97 \\
\hline
\end{tabular}

Composite Reliability (CR). "Cronbach's alpha is the most common measure of internal consistency reliability" (Hair et al., 2011). The Cronbach's Alpha test results also confirmed the appropriateness of the measurement model fit. A Cronbach's Alpha and CR of above 0.7 are desired to support the model fitness (Tsai et al., 2021). We also assessed the convergence validity using Average Variance Extracted (AVE), as displayed in Table 3. AVE values above 0.5 are evidence of convergence validity (Tsai et al., 2021).

The correlation between financial and centrality measures is presented in the appendix section. Appendix 1, Table B1 displays the correlation of all financial measures across the three timelines, 1, 2, and 5 years. Strong correlations above 0.8 are present for some financial measures across the three timelines, which supports analyzing the data through three separate models. Correlations above 0.8 are generally of concern since it could imply that the variable pairs are too similar to measure different concepts. Tables B2, B3, and
B4 (Appendix 1) represent the three correlation tables separately which Table B5 (Appendix 1) displays the correlations among measures of centralities, where no correlations above 0.65 are present. Since the measurement of centrality in this research is a novel approach to study supply chain networks, we also conducted VIF tests of multicollinearity using SPSS. Five VIF tests were conducted for factors of centrality, and they are presented in Table C1 of Appendix 1. Generally, VIF is desired to be less than 4, and a VIF "between 5 and 10" might suggest "mild multicollinearity" (O'Brein, 1980 as cited in Chang \& Mastrangelo, 2011). All of the VIFs in our analysis were found to be less than 2, which further supports our measurement model's strength. Further descriptive statistics are presented in Table C2 of Appendix 1.

According to the result of our explanatory analysis, a fivefactor model can best illustrate various aspects of the firms' position in our sample of supply chain network. The first factor (C1) includes the most number of measures and it is consists of in-degree, betweenness, authority, pagerank, and eigenvector. The second factor (C2) consists of out-degree and hub, the third factor (C3) consists of triangles and cluster size, and the fourth factor (C4) consists of closeness and strong component. Finally, the fifth factor (C5), is a single measure factor based on bridging centrality.

Beta, market price volatility, and return on assets were used to measure various aspects of financial performance, risk, and market volatility. Since there is no previous study on the most effective time lag of the relationship between centrality measures and financial/volatility measures, we decided to obtain financial, risk, and volatility measures in three periods for each measure, namely 1 year, 2 years, and 5 years. This approach provided exciting findings that will be discussed in the following section through the path analyses for the three periods.

\section{Path Analysis}

Path analysis was used to measure the effect of various aspects of centrality on market volatility, risk, and firms' performance. As mentioned previously, there is a time lag between organizational circumstances and the observed financial, operational, and market performance of firms. We expected this effect to differ in different timelines. For this reason, the path analysis was conducted three times, using the 1-year, 2-year, and 5-year models (Fig. 5). The model metrics are also presented in Table C3 of Appendix 1.

In conducting the analysis, two main modifications were made to enhance the model fit. The first modification was about adding error covariance between Beta and return on asset as suggested by LISREL to improve the model fitness. The second modification was to remove the fifth measure of centrality (C5) due to its negative effect on model 


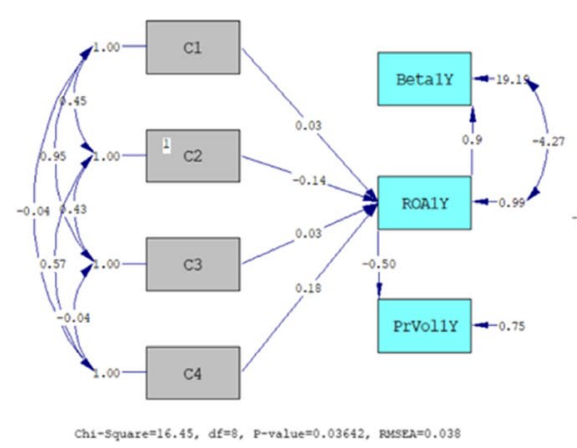

* Beta: asset risk ROA: return on assets

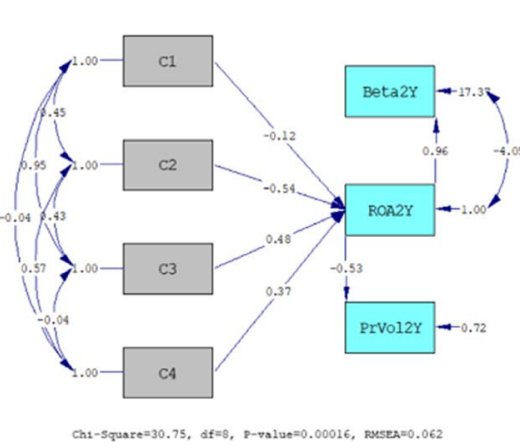

PrVol: price volatility

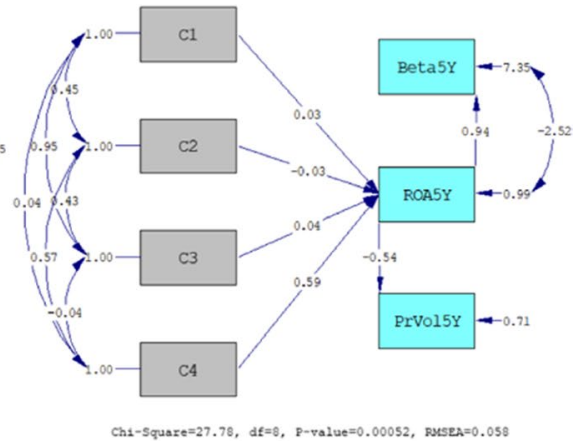

Chi-square $=27.78$, df $=8, p-v a l u e=0.00052$, porseA $=0.058$

Fig. 5 The role of the centrality in firm performance, risk and market volatility: 1, 2, and 5 years*

convergence and fitness. All path coefficients are significant at 0.05 level.

"EFA is appropriate when there is limited theoretical precedent for a model, as the number of dimensions and their association with observed variables are determined based on the data. In Confirmatory Factor Analyses (CFA), on the other hand, models are theory-driven, and the research must specify the hypothesized number of dimensions associated with each [construct]." (Ametti and Althoff, 2019, pp: 34). For well-defined and highly researched measurement models, CFA would be recommended. To conduct factor analysis for a theory-driven model, each factor is preferred to have at least three measures associated with its formation (Hair et al., 2010). However, the recommended number of measures for each factor is not data-driven; rather, it is a recommendation for refinement of theory (Ab Hamid et al., 2011; Taherdoost et al., 2014). Factor analysis is not a tool to determine the model; factor analysis is for "assisting in the process of construct identification", instead of "exclusively relying on intuition and theory" (Fabrigar \& Wegener, 2012, pp: 21). As the present work is one of the early studies on the application of centrality in supply chain structures, and due to the lack of previous theory-driven models, EFA would be an appropriate analysis tool. Therefore, the use of single measure factors is justified, particularly when we consider theoretical support for each of the centrality measures described before. Furthermore, the use of single measure factors has been well documented in psychometric analytics (c.f. Raghunathan et al., 1999; Taylan et al., 2020; Zhao et al., 2018).

As this work's nature is explanatory, a decision was made to keep the fifth factor in the early stages of the analysis and only remove the factor if the model fitness is not acceptable. Based on the study results, the fifth factor was removed from the models to enhance the model fitness as the models would not converge or would display poor model fitness when the fifth factor was present. To evaluate the model fitness p-values, RMSEA, ratio of chi-square to the degrees of freedom, normed fit index, non-normed fit index, comparative fit index, and relative fit index were evaluated (Table A10, Appendix 1).

In reviewing the model fitness, we observe that the p-values are less than 0.05 , which does not support the models' goodness of fit. It is important to note that using p-value as a measure of fitness is reported to show problems when "sample size exceed[s] 200" (Hair et al., 1992 as cited in Boe, 2015). Barrett (2007) argues that relying on chi-square due to its sensitivity to "increasing sample sizes can be highly problematic," particularly in exploratory studies (see also Ashktorab et al., 2015). Due to the sensitivity of "chi-square statistic as a measure of overall fit to both sample size and distribution of observed variables" (Etezadi-Amoli \& Farhoomand, 1996; c.f. Fornell, 1983; Bentler \& Bonett, 1980), we instead use the ratio of $\chi^{2}$ to degrees of freedom (c.f. Etezadi-Amoli \& Farhoomand, 1996) and RMSEA (c.f. Ensink et al., 2017). The chi-square to degrees of freedom ratio lower than three is qualified as perfect suitability (Kahraman \& Ceylan, 2020), while ratios between three and five are considered acceptable fitness (Bollen, 1989, as cited in Park et al., 2011). The RMSEA of less than 0.05 is a "robust indicator" of the perfect suitability of the model, while values "less than 0.08 " are considered good model fitness (Browne \& Cudeck, 1993 as cited in Park et al., 2011). In the following section, the result of the study is discussed.

\section{Discussion of Findings}

The analysis findings provide fruitful insight into our understanding of supply chain structure's role -as measured by various aspects of centrality- in firms' financial performance, market volatility, and investment risk. The exploratory analysis findings suggest that a five-factor model can best describe various aspects of supply chain centrality. We 
did not observe evidence of very strong correlations among measures of centrality that further supports the utilization of the five-factor model. The path analysis recommended that a four-factor model be more suitable for studying the relationships among dependent and independent variables. After discussing the exploratory analysis findings, the discussion of the path analysis results is presented in this section.

One of the exciting findings of the exploratory analysis is that out-degree and in-degree are identified to present different centrality aspects. The first factor (C1) includes indegree, betweenness, authority, pagerank, and eigenvector. Many of these measures (particularly authority, pagerank, and eigenvector) emphasize the quality of connection points. Considering supply in-degree and authority in one factor has theoretical support from supply chain literature (c.f. Borgatti $\& \mathrm{Li}, 2009)$. We define $\mathrm{C} 1$ as strategic buyer centrality (SBC). Companies with higher $\mathrm{C} 1$ are producing more complex products, and they are closer to the auto industry's final products (Nuss et al., 2016). The finding is aligned with the industry structure we discussed previously that this industry has a relatively small number of large players, mainly part assemblers. A strategic buyer with a higher level of bargaining represents influence throughout the supply chain network based on its "power of alliance within the members of supply network" (Oliveira \& Gimeno, 2014, p.151).

The second factor (C2) includes out-degree and hub. Out-degree outlines the number of customers and identifies firms that offer a higher variety of products (Nuss et al., 2016) while firms with a higher hub centrality "face serious competition in selling their goods, but have a good situation with respect to their suppliers" (Borgatti \& Li, 2009). We define $\mathrm{C} 2$ as an active seller centrality (ASC). The third factor (C3) includes triangles and cluster size. This result is interesting due to the relationship between triangles and cluster size of firms. As we discussed earlier, triangles and cluster size are the only two community-related measures of centrality in this work. While triangles centrality is a local measure, cluster size is a global measure of centrality. C3's conceptual interpretation's alignment with the exploratory analysis result is further evidence for the sound research design and execution in the present work.

C3 measure represents the size of a firm's immediate and close partners in its community. We define $\mathrm{C} 3$ as community cluster centrality (CCC). A higher degree of community cluster may be interpreted as a high integration of a firm's operations in a more influential community of firms, resulting in higher stability and lower uncertainty. CCC can be viewed as a measure of firm's immergence in more influential ecosystems across the global supply chain.

The fourth factor (C4) includes closeness (reversed ranked) and strong component. To normalize the closeness data, we first rank-ordered the closeness measure. It is important to note that when conducting EFA, closeness and strong component were found to be under one factor; however, the factor loading for closeness centrality was negative. We reversed the rank order for a more straightforward presentation and discussion of the results; this should be noted in any interpretation of the results. A lower level of closeness and a higher level of strong component will lower the firm's exposure to risk and volatility. In the context of supply chain closeness and strong component, these measures can represent "information centrality" and network reach (Borgatti \& $\mathrm{Li}, 2009)$. Firms that are close to several key market players have access to and are part of the network's knowledge ecosystem. We define $\mathrm{C} 4$ as reach $\boldsymbol{\&}$ information centrality (RIC). Finally, the fifth factor (C5) is a single measure construct consisting of bridging centrality. We define bridging centrality as per its single component.

According to the result of path analysis, the role of centrality measures in our sample can be most significantly observed with the 2-year model. In contrast, the least effect of centrality on financial performance was observed in the 5 -year model. This is an interesting finding as it provides the first evidence of the role of time in the relationship between centrality and financial performance. According to this result, the firms' supply chain structure is more relevant to the two-year model. The supply chain data are collected mostly from publicly traded firms that are mandated to report their notable suppliers and customers over the past 3 years. The financial reporting mandate for publically traded firms can (at least partially) explain why the twoyear model shows the most effect on relationships. Another reason for the two-year model's effectiveness could be the two-fold effect of the supply chain position timeline on firms' performance: on one the hand, the supply chain data structure is changing at a pace that the 5 -year model shows the least amount of compatibility with the firm's current performance; On the other hand, due to the performance lag, the 1-year model performance cannot reflect the existing supply chain structure's effect through the current performance metrics.

A more detailed review of the results across the three timelines reveals that RIC is the only centrality measure that has a notable impact on firms' performance across all three models. ASC is notable only in the 1-year and 2-year model, and its impact is negative on firms' performance. Similarly, SBC's effect on firms' performance is negative, although the effect is lower and only notable in the 2-year model. We argue that firms that are highly oriented toward working with a large number of buyers or sellers will have a lower profit margin due to their location in the supply chain, where they are providing more standardize and/or less complex products and services with smaller profit margin. The SBC exhibits a smaller negative impact on firms' performance in comparison to ASC. We further argue that a larger number of firms with higher ASC are engaged in low value-added 
products/services in comparison to high SBC firms. More studies using categorical analysis are recommended to differentiate high SBC firms from low SBC firms. Firms with higher CCC were also found to have better financial performance due to their location in denser supply chain networks, as suggested in the literature (Li et al., 2020).

Future research could further explore this relationship with a larger time gap (e.g., 7-year gap) to investigate the point of time at which the supply chain structure changes to the extent that it cannot reflect any effect of firm performance stemming from the centrality measures.

Another interesting finding is that firms with higher SBC and ASC levels have lower levels of return on assets; the strength of this relationship is low to moderate. This result is contrary to our hypothesis; while there exists a relationship, this relationship is mostly negative across the three models. The reason could be explained through first-order capabilities versus second-order capabilities. Firms with high SBC and ASC are generally the legacy firms, with a highly vertically integrated supply chain which are expected to benefit based on transaction cost theory. However, such firms are less capable of adapting to the changing business environment and suffer from a lower level of dynamic capabilities-or what Reeves and Deimler (2011) describe as second-order capabilities-which we discussed previously. The lack of second-order capabilities seems to outweigh the benefits that firms acquire from high first-order capabilities and/or their transaction cost advantages.

Firms with higher CCC levels and RIC seem to have moderately better financial performance in the two-year model. This result is in line with our hypothesis and the previous literature discussing that network connections create a network community that results in higher synergy among firms and achievement of more second-order capabilities (c.f. McCormack et al., 2002; Petricevic \& Verbeke, 2019).

The findings also suggest that better financial performance measured by return on assets results in higher Beta (measured in the rank order as lower risk) and lower price volatility in the market. This relationship exists across all three models. In the next sections, the paper's synthesis and application of the research, along with limitations and directions for future studies, are discussed.

\section{Synthesis and Contributions}

This work is an early approach to our understanding of network science application in the study of global supply chains and firms' competitiveness. There has been significant progress in applying network science in social networking, physics, mathematics, and other research areas. However, relatively few studies have explored such research in the area of the organizational supply chain. The limited number of research in this area has been partially due to the limitations around access to supply chain network data. Although data availability in this field is still limited, we have used innovative techniques to mine and prepare supply chain data from the financial data sources. While these data are of high quality for larger firms, data from private and smaller firms are limited.

This exploratory study provides a method to identify various aspects of the supply chain network for the automanufacturing sector. Researchers and practitioners can utilize the same techniques to uncover the underlying patterns of network structures specific to other industries. One of this work's notable contributions is the exploratory reach conducted to produce the five-factor model of supply chain centrality measurement. Future research can apply the same measurement methodology to develop centrality measures in other industries and higher supply chain tiers.

Another significant contribution of this work is studying the effect of firms' position in the supply chain on various aspects of the firms' financial performance (as measured by return on asset), asset risk (as measured by Beta), and market volatility performance (as measured by firms market value). Researchers and practitioners can utilize other centrality measures and performance metrics using the analytical methodologies presented in this paper. One of the notable findings of this reach was that the relationship between firms' performance and their position in the supply chain network is most visible with a two-year model. Additionally, academics and practitioners can use the research approach used in this study to design short-term and long-term strategic goals, which are more effectively aligned with other firms' performance targets and the strategic position of the firms in the globally connected supply chain network.

\section{Limitations}

The main limitation of this study is associated with the availability of the supply chain and financial data. While the information about supply chain networks is more readily available for major actors in the global supply chain through financial reports released by publically traded firms, the availability of such data for smaller and privately owned firms is limited. Additionally, financial performance information is limited to publicly traded companies around the world. Hence, while the centrality measures are calculated for the total sample population, the analysis of the financial performance is limited mostly to the population of publicly traded companies. Another limitation of the study is the scope of research in measuring financial, risk, and volatility. As there are various measures of firms' performance, risk, and volatility, the researchers and practitioners need to select the appropriate financial measures for their analysis goal. As a benchmark study in the field, a decision was made to use popular performance measures; future studies can select 
other more specific measures to assess various aspects of firms' performance and competitiveness. We hope future studies can address these limitations.

\section{Future Studies}

This study presents a global supply chain study in one industry at the firm level. Future studies can include the network of professionals working in firms around the world at the individual level. The present study explores the tier-one supply chain associated with primary activities and actors involved in support activities. Future studies are encouraged to explore multi-tier supply chain networks. The data for this study were collected in late 2019 before the global COVID19 pandemic. Since COVID-19 is expected to affect the global manufacturing patterns and competitiveness (Deshmukh \& Haleem, 2020), future studies are encouraged to be conducted after the pandemic to assess any changes in the global manufacturing patterns. Fruitful research opportunities exist in investigating the supply chain resilience in other key industries such as the global supply chain of medical equipment and conducting analysis at the firm level, industry level, and country level.

\section{Key Questions Reflecting Applicability in Real Life}

In what contexts, a firm's supply chain connections can enhance competitiveness processes?

How a firm's position in the global supply chain affects its financial performance?

Can a firm's centrality measure in the global supply chain influence its asset price volatility?

How centrality measures determine a firm's strategic position in the global supply chain network?

\section{Clustering Analysis Data}

\section{https://github.com/businessecosystem/AutoSupplyChain}

Supplementary Information The online version contains supplementary material available at https://doi.org/10.1007/s42943-021-00026-8.

\footnotetext{
Acknowledgements This project is part of the ongoing research projects conducted by the Innovation \& Entrepreneurship Business Ecosystem Lab (IEBE Lab) supported by the University of North Carolina System's inter-institutional planning research grant. We would like to convey our great appreciation to the editors and anonymous reviewers. Their careful review of the work and valuable recommendation made an important contribution to the work.
}

Conflict of Interest On behalf of all authors, the corresponding author states that there is no conflict of interest.

\section{References}

Ab Hamid, M. R., Mustafa, Z., Idris, F., Abdullah, M., \& Suradi, N. R. M. (2011). Measuring value-based productivity: A Confirmatory Factor Analytic (CFA) approach. International Journal of Business and Social Science, 2(6), 85-93.

Ametti, M., \& Althoff, R. R. (2019). Measurement of irritability in children and adolescents. In A. K. Roy, M. A. Brotman, \& E. Leibenluft (Eds.), Measurement of irritability in children and adolescents. Oxford University Press. https://doi.org/10.1093/ med-psych/9780190846800.003.0003

Ashktorab, T., Hasanvand, S., Seyedfatemi, N., Zayeri, F., Levett-Jones, T., \& Pournia, Y. (2015). Psychometric testing of the Persian version of the belongingness Scale-clinical placement experience. Nurse Education Today, 35, 439-443. https://doi.org/10.1016/j. nedt.2014.11.006

Baglin, J. (2014). Improving your exploratory factor analysis for ordinal data: A demonstration using FACTOR. Practical Assessment, Research, and Evaluation, 19(5), 1-14.

Barney, J. B. (1999). How a Firm's capabilities affect boundary decisions. Sloan Management Review, 40(3), 137-145.

Barrett, P. (2007). Structural equation modelling: Adjudging model fit. Personality and Individual Differences, 42(5), 815-824. https:// doi.org/10.1016/j.paid.2006.09.018

Basole, R. C., Ghosh, S., \& Hora, M. (2018). Supply network structure and firm performance: Evidence from the electronics industry. IEEE Transactions on Engineering Management, 65(1), 141-154. https://doi.org/10.1109/tem.2017.2758319

Basole, R. C., Park, H., \& Barnett, B. C. (2015). Coopetition and convergence in the ICT ecosystem. Telecommunications Policy, 39, 537-552. https://doi.org/10.1016/j.telpol.2014.04.003

Bentler, P. M., \& Bonett, D. G. (1980). Significance tests and goodness of fit in the analysis of covariance structures. Psychological Bulletin, 88(3), 588-606. https://doi.org/10.1037/0033-2909.88.3.588

Benzi, M., Estrada, E., \& Klymko, C. (2013). Ranking hubs and authorities using matrix functions. Linear Algebra and Its Applications, 438(5), 247-2474. https://doi.org/10.1016/j.laa.2012.10.022

Benzi, M., \& Klymko, C. (2015). On the limiting behavior of parameter-dependent network centrality measures. SIAM Journal on Matrix Analysis and Applications, 36(2), 686-706. https://doi. org/10.1137/130950550

Bertalanffy, L. V. (1950). The theory of open systems in physics and biology. Science Magazine, 111(2872), 23-29. https://doi.org/10. 1126/science.111.2872.23

Bertalanffy, L. V. (1968) General Systems Theory. New York: George Braziller

Besri, Z., \& Boulmakoul, A. (2017). Framework for organizational structure re-design by assessing logistics' business processes in harbor container terminals. Transportation Research Procedia, 22, 164-173. https://doi.org/10.1016/j.trpro.2017.03.023

Blondel, V. D., Guillaume, J.-L., Lambiotte, R., \& Lefebvre, E. (2008). Fast unfolding of communities in large networks. Journal of Statistical Mechanics: Theory and Experiment., 2008(10), 1-12. https://doi.org/10.1088/1742-5468/2008/10/p10008

Boe, O. (2015). Using LISREL V to perform a covariance structure analysis of a tripartite model of attitude. Procedia Social and Behavioral Sciences, 182, 360-363. https://doi.org/10.1016/j. sbspro.2015.04.786

Bollen, K. A. (1989). Structural equations with latent variables. Wiley. https://doi.org/10.1002/9781118619179 
Borgatti, S., \& Li, X. (2009). On social network analysis in a supply chain context. Journal of Supply Chain Management, 45(2), 5-22. https://doi.org/10.1111/j.1745-493x.2009.03166.x

Browne, M. W., \& Cudeck, R. (1993). Alternative ways of assessing model fit. In K. A. Bollen \& J. S. Long (Eds.), Testing structural equation models (pp. 136-162). Sage.

Burgers, W. P., Hill, C. W., \& Kim, W. C. (1993). A theory of global strategic alliances: The case of the global auto industry. Strategic Management Journals, 14(6), 419-432. https://doi.org/10.1002/ smj.4250140603

Calleja-Blanco, J., \& Grifell-Tatje, E. (2016). Potential Coopetition and Productivity Among European Automobile Plants. In Aparicio, J., Lovell, C.A.K., \& Pastor, J. P. (Eds.) Advances in efficiency and productivity, volume 249 of the series international series in operations research \& management science (pp: 249-273). Doi: https://doi.org/10.1007/978-3-319-48461-7_11

Chang, Y. C., \& Mastrangelo, C. (2011). Addressing multicollinearity in semiconductor manufacturing. Quality and Reliability Engineering International, 27(6), 843-854. https://doi.org/10.1002/ qre. 1173

Chen, I. J., \& Paulraj, A. (2004). Towards a theory of supply chain management: The constructs and measurements. Journal of Operations Management, 22(2), 119-150. https://doi.org/10.1016/j. jom.2003.12.007

Chen, J., Xu, Z., Huang, D., Fang, C., Wang, X., \& Zhang, J. (2020). Automotive supply chain networks equilibrium model under uncertain payment delay and objective weights. Computer \& Industry Engineering, 150, 106866.

De Mello-Sampayo, F. (2017). Competing-destinations gravity model applied to trade in intermediate goods. Applied Economics Letters, 24(19), 1378-1384. https://doi.org/10.1080/13504851.2017. 1282109

Deshmukh, S. G., \& Haleem, A. (2020). Framework for Manufacturing in Post-COVID-19 World Order: An Indian Perspective. International Journal of Global Business and Competitiveness, 15(1), 49-60. https://doi.org/10.1007/s42943-020-00009-1

Dixit, V., Verma, P., \& Tiwari, M. K. (2020). Assessment of pre and post-disaster supply chain resilience based on network structural parameters with $\mathrm{CVaR}$ as a risk measure. International Journal of Production Economics, 227, 1-17. https://doi.org/10.1016/j. ijpe.2020.107655

Dyer, J. H., \& Singh, H. (1998). The relational view: Cooperative strategy and sources of interorganizational competitive advantage. Academy of Management Review, 23(4), 660-679. https:// doi.org/10.2307/259056

Ensink, K., Berthelot, N., Begin, M., Maheux, J., \& Normandin, L. (2017). Dissociation mediates the relationship between sexual abuse and child psychological difficulties. Child Abuse \& Neglect, 69, 116-124. https://doi.org/10.1016/j.chiabu.2017.04.017

Etezadi-Amoli, J., \& Farhoomand, A. F. (1996). A structural model of end user computing satisfaction and user performance. Information \& Management, 30(2), 65-73. https://doi.org/10.1016/03787206(95)00052-6

Fabrigar, L. R., \& Wegener, D. T. (2012). Exploratory factory analysis: Understanding statistics. Oxford University Press Inc.

Fornell, C. (1983). Issues in the application of covariance structure analysis: A comment. Journal of Consumer Research, 9(3), 443448. https://doi.org/10.1086/208938

Foss, N. J. (1999). Edith Penrose, economics and strategic management, Contributions to Political Economy, 18(1), 87-104. https:// doi.org/10.1093/cpe/18.1.87

Graca, P., \& Camarinha-Matos, L. M. (2017). Performance indicators for collaborative business ecosystems-literature review and trends. Technological Forecasting \& Social Change, 116, $237-$ 255. https://doi.org/10.1016/j.techfore.2016.10.012
Grover, V., \& Malhotra, M. K. (2003). Transaction cost framework in operations and supply chain management research: Theory and measurement. Journal of Operations Management, 21(4), 457473. https://doi.org/10.1016/s0272-6963(03)00040-8

Guillot, D., \& Lincoln, J. R. (2001). The permeability of network boundaries: strategic alliances in the Japanese electronics industry in the 1990s. In: Proceedings of the annual meeting of The Academy of Management. Washington, D.C. 2001. URL: https:// hermes-ir.lib.hit-u.ac.jp/hermes/ir/re/13967/wp2001-6a.pdf [Last accessed 15/6/2021]

Gulati, R. (1995). Social structure and alliance formation patterns: A longitudinal analysis. Administrative Science Quarterly, 40(4), 619-652. https://doi.org/10.2307/2393756

Gulati, R., \& Garguilo, M. (1999). Where do interorganizational networks come from? American Journal of Sociology, 104(5), 1439-1493. https://doi.org/10.1086/210179

Gulbrandsen, B., Lambe, C. J., \& Sandvik, K. (2017). Firm boundaries and transaction costs: The complementary role of capabilities. Journal of Business Research, 78, 193-203. https://doi.org/10. 1016/j.jbusres.2016.12.015

Guo, C., Liu, X., Jin, M., \& Lv, Z. (2016). The research on optimization of auto supply chain network robust model under macroeconomic fluctuations. Chaos, Solitons and Fractals, 89, 105-114. https:// doi.org/10.1016/j.chaos.2015.10.008

Hair, J. F., Anderson, R. E., Tatham, R. L., \& Black, W. C. (1992). Multivariate data analyses. Macmillan Publishing Company.

Hair, J. F., Black, W. C., Babin, B. J., \& Anderson, R. E. (2010). Multivariate data analysis (7th ed.). Prentice-Hall.

Hair, J. F., Sarstedt, M., \& Ringle, C. M. (2011). An assessment of the use of partial least squares structural equation modeling in marketing research. Journal of the Academy of Marketing Science, 40, 414-433.

Hanaka, T., Kagawa, S., Ono, H., \& Kanemoto, K. (2017). Finding environmentally critical transmission sectors, transactions, and paths in global supply chain networks. Energy Economics, 68, 44-52. https://doi.org/10.1016/j.eneco.2017.09.012

IBISWorld (2017). Industry research reports.

Kahraman, A., \& Ceylan, S. S. (2020). Psychometric properties of the Turkish version of the developmental support competency scale for nurses (DSCS-N). Journal of Pediatric Nursing, 54, 47-52. https://doi.org/10.1016/j.pedn.2020.04.021

Kohtamäki, M., \& Rajala, R. (2016). Theory and practice of value cocreation in B2B systems, theory and practice of value co-creation in B2B systems. Industrial Marketing Management, 56, 4-13. https://doi.org/10.1016/j.indmarman.2016.05.027

Langville, A. N., \& Meyer, C. D. (2011). Deeper inside pagerank. Internet Mathematics, 1(3), 335-380. https://doi.org/10.1080/ 15427951.2004.10129091

Lavassani, K. (2017). Coopetition and sustainable competitiveness in business ecosystem: A networks analysis of the global telecommunications industry. Transnational Corporate Review, 9(4), 281-308. https://doi.org/10.1080/19186444.2017.1401207

Lavassani, K., \& Movahedi, B. (2018). Achieving higher supply chain performance via business process orientation. Business Process Management Journal, 24(3), 671-694. https://doi.org/10.1108/ bpmj-07-2016-0140

Leskovec, J., Lang, K. J., Dasgupta, A., \& Mahoney, M. W. (2009). Community structure in large networks: Natural cluster sizes and the absence of large well defined clusters. Internet Mathematics, 6(1), 29-123. https://doi.org/10.1080/15427951.2009.10129177

Li, T. (2021). Algorithm optimization of large-scale supply chain design based on FPGA and neural network. Microprocessors and Microsystems, 81, 1-6. https://doi.org/10.1016/j.micpro.2020. 103790

Li, Y., Zobel, C. W., Seref, O., \& Chatfield, D. (2020). Network characteristics and supply chain resilience under conditions of risk 
propagation. International Journal of Production Economics, 223, 1-13. https://doi.org/10.1016/j.ijpe.2019.107529

Long, C., \& Vichers-Koch, M. (1995). Using Core capabilities to create competitive advantage. Organizational Dynamics, 24(1), 7-22. https://doi.org/10.1016/0090-2616(95)90032-2

McCormack, K. P., Johnson, W. C., \& Walker, W. T. (2002). Supply chain networks and business process orientation. St. Lucie Press. https://doi.org/10.1201/9781420000344

Momaya, K. S. (2001). International competitiveness: Evaluation and enhancement. Hindustan Publishing Corporation.

Momaya, K. S. (2019). The past and the future of competitiveness research: A review in an emerging context of innovation and EMNEs. International Journal of Global Business and Competitiveness, 14(1), 1-10. https://doi.org/10.1007/ s42943-019-00002-3

Moons, K., Waeyenbergh, G., \& Pintelon, L. (2019). Measuring the logistics performance of internal hospital supply chains-a literature study. Omega, 82(C), 205-217. https://doi.org/10.1016/j. omega.2018.01.007

Moore, J. F. (1993). Predators and prey a new ecology of competition. Harvard Business Review, 71(3), 75-86.

Moore, J. F. (1996). The death of competition: Leadership and strategy in the age of business ecosystems. HarperBusiness.

Nuss, P., Graedel, T. E., Alonso, E., \& Carroll, A. (2016). Mapping supply chain risk by network analysis of product platforms. Sustainable Materials and Technologies, 10, 14-22. https://doi.org/ 10.1016/j.susmat.2016.10.002

O'Brien, R. M. (1980). A caution regarding rules of thumb for variance inflation factors. Quality and Quantity, 41(5), 673-690. https:// doi.org/10.1007/s11135-006-9018-6

Oliveira, A., \& Gimeno, A. (2014). Managing supply chain networks: Building competitive advantage in fluid and complex environments. Pearson FT Press.

Park, N., Jung, Y., \& Lee, K. M. (2011). Intention to upload video content on the internet: The role of social norms and ego-involvement. Computers in Human Behavior, 27(5), 1996-2004. https:// doi.org/10.1016/j.chb.2011.05.006

Petricevic, O., \& Verbeke, A. (2019). Unbundling dynamic capabilities for inter-organizational collaboration: The case of nanotechnology. Cross Cultural \& Strategic Management, 26(3), 422-448. https://doi.org/10.1108/ccsm-02-2019-0044

Pitelis, C. N., \& Wahl, M. W. (1998). Edith Penrose: Pioneer of stakeholder theory. Long Range Planning, 31(2), 252-261. https://doi. org/10.1016/s0024-6301(98)00009-0

Raghunathan, B., Raghunathan, T. S., \& Tu, Q. (1999). Dimensionality of the strategic grid framework: The construct and its measurement. Information Systems Research, 10(4), 343-355. https://doi. org/10.1287/isre.10.4.343

Rajeh, S., Savonnet, M., Leclercq, E., \& Cherifi, H. (2021). Investigating centrality measures in social networks with community structure. In R. M. Benito, C. Cherifi, H. Cherifi, E. Moro, L. M. Rocha, \& M. Sales-Pardo (Eds.), Complex networks \& their applications IX. COMPLEX NETWORKS 2020 2020. Studies in computational intelligence. (Vol. 943). Cham: Springer. https:// doi.org/10.1007/978-3-030-65347-7_18

Reeves M., \& Deimler M. (2011). Adaptability: The new competitive advantage, Harvard Business Review, July-August, pp:19-26. https://doi.org/10.1002/9781119204084.ch2

Ritala, P., Golnam, A., \& Wegmann, A. (2014). Coopetition-based business models: The case of Amazon.com. Industrial Marketing
Management, 43(2), 236-249. https://doi.org/10.1016/j.indma rman.2013.11.005

Schriber, S., \& Löwstedt, J. (2019). Reconsidering ordinary and dynamic capabilities in strategic change. European Management Journal, 38(3), 377-387. https://doi.org/10.1016/j.emj.2019.12. 006

Scott, R. (2003). Organizations: Rational, natural and open systems. Prentice-Hall.

Seiler, A., Papanagnou, C., \& Scarf, P. (2020). On the relationship between financial performance and position of business in supply chain networks. International Journal of Production Economics, 227, 1-14. https://doi.org/10.1016/j.ijpe.2020.107690

Stolze, H. J., Mollenkopf, D. A., Thornton, L. D., Brusco, M. J., \& Flint, D. J. (2018). Supply chain and marketing integration: Tension in frontline social networks. Journal of Supply Chain Management, 54(3), 3-21. https://doi.org/10.1111/jscm.12169

Taglioni, D., \& Winkler, D. (2016). Making global value chains work for development. World Bank Group. https://doi.org/10.1596/9781-4648-0157-0_fm

Taherdoost, H., Sahibuddin S., and Jalaliyoon, N (2014). Exploratory factor analysis; Concepts and theory. Jerzy Balicki. Advances in applied and pure mathematics, 27, WSEAS, pp. 375-382, 2014, Mathematics and computers in science and engineering series, 978-960-474-380-3. 〈hal-02557344〉

Tang, J., Musolesi, M., Mascolo, C., \& Latora, V. (2010). Characterising temporal distance and reachability in mobile and online social networks. ACM SIGCOMM Computer Communication Review, 40(1), 118-124. https://doi.org/10.1145/1672308.1672329

Taylan, S., Ozkan, I., \& Celik, G. K. (2020). The validity and reliability analysis of the Turkish version of the 8-item passion scale. New Ideas in Psychology., 59, 1-6. https://doi.org/10.1016/j.newid eapsych.2020.100802

Thacker, E. (2004). Biomedia. Univesity of Minnesota Press.

Tsai, M. C., Wang, J. F., \& Chen, Y. T. (2021). Effect of social identity on supply chain technology adoption of small businesses. Asia Pacific Management Review. https://doi.org/10.1016/j.apmrv. 2020.12.001

Williamson, O. E. (1975). Markets and hierarchies: Analysis and antitrust implications. The Free Press.

Williamson, O. E. (1981). The modern corporation: Origins, evolution, attributes. Journal of Economic Literature, 19(4), 1537-1568.

Williamson, O. E. (2005). Transaction cost economics. In C. Menard \& M. Shirley (Eds.), Handbook of new institutional economics (pp. 41-65). Springer. https://doi.org/10.1007/0-387-25092-1_4

Yeung, J. H. Y., Selen, W., Zhang, M., \& Huo, B. (2009). The effects of trust and coercive power on supplier integration. International Journal of Production Economics, 120(1), 66-78. https://doi.org/ 10.1016/j.ijpe.2008.07.014

Zhao, P., Yin, S., Han, X., \& Zhuyue, L. (2021). Research on lean supply chain network model based on node removal. Physica a: Statistical Mechanics and Its Applications, 567, 1-14. https://doi. org/10.1016/j.physa.2020.125556

Zhao, X., Pan, W., \& Chen, L. (2018). Disentangling the relationships between business model innovation for low or zero carbon buildings and its influencing factors using structural equation modelling. Journal of Cleaner Production, 178, 154-165. https://doi. org/10.1016/j.jclepro.2018.01.010 


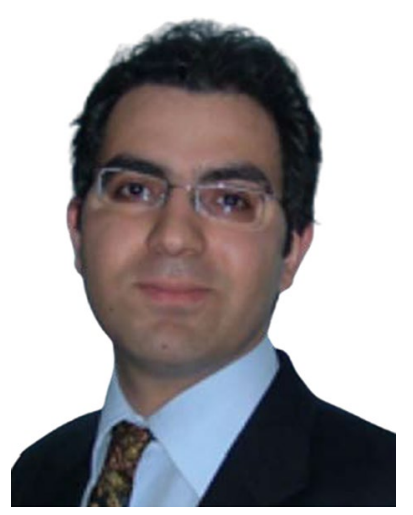

Kayvan Miri Lavassani Ph.D., is an associate professor with the School of Business (AACSB) at North Carolina Central University. Dr. Lavassani has worked with private, public, and third sector organizations in areas of manufacturing, technology, international trade, and investment in the United States and internationally. $\mathrm{He}$ is the cofounder and director of the Innovation \& Entrepreneurship Business Ecosystem Lab (IEBE Lab), where he promotes the study of business ecosystems using com-

plex data and network analytics tools. Dr. Lavassani is currently serving as an editor of the Journal of Business Ecosystems (JBE).

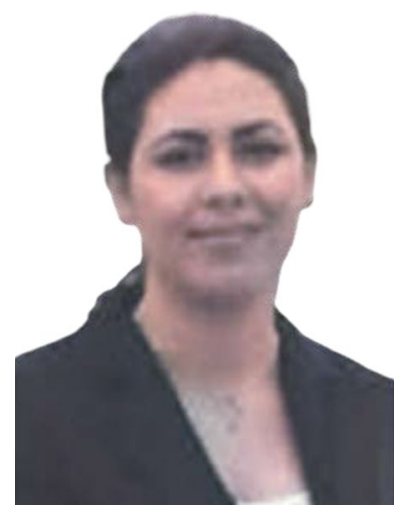

Bahar Movahedi Ph.D., teaches decision sciences at North Carolina Central University's School of Business (AACSB). She has over 60 publications in journals, books, and conferences. She has received several awards honoring the quality of her publications from prestigious institutions in Canada, the United Kingdom, and the United States. Dr. Movahedi is currently serving as the Associate Editor of the Journal of Business Ecosystems (JBE). 